\title{
The Language of College Dating: A Gender Study
}

\section{Michelle Tomassi}

\section{INTRODUCTION}

It's no surprise that the concept of dating takes on a whole new meaning for college students. At Boston College, as well as other universities across the country, the hook-up culture has complicated the notion of dating, and students use a wide variety of terms to distinguish between casual hook-ups and serious relationships. There is also a spectrum of language that describes the various stages of a relationship's progression: two students may "be a thing" before they are dating, which will eventually lead to their "being together" or "being in a relationship." On the flip side, students who want "no-strings-attached" might just want to hook up with someone or start "talking" to someone, carefully avoiding any terminology associated with the word "date." The idea of going on a date seems to be a more formalized process with stronger emotional connotations, and might cause fear of commitment among students just looking to have fun.

The social aspect of dating has been studied extensively among sociologists, but it is not often looked at from a linguistic perspective. Kerry Cronin, associate director of the Lonergan Center and a professor of philosophy at BC, is well known for her studies of dating and the college hook-up culture; she gives annual talks such as "Bring Back the Date" and actually taught a Capstone class in which she assigned her students to go on various types of dates. ${ }^{1}$ Cronin explained to me that she had not come across any literature in her studies dealing with the linguistic aspect of dating, but affirmed that there definitely is a difference among men and women when it comes to discussion of these topics. Male students, she explained, generally need more prompting to describe certain aspects of dating. Female students, on the other hand, seem to have a more performative range - including a larger lexicon and a wider range of expressions - for depicting the types of dating in college. Therefore, I decided to test the theory that female college students have a larger spectrum of language to describe the various forms of college dating than male students do, although both male and female students have the same attitudes toward these forms and tend to use language that avoids the concept of "the date."

\section{Methodology}

The subjects involved in my study include male and female students at Boston College, and I decided to focus on gender rather than age. I interviewed sophomores, juniors, and seniors; I excluded freshmen because I wanted to make sure that my subjects were fully immersed in the college dating culture, and that they did not express any of their high school experiences and beliefs, which is more likely with freshmen students in their first semester of college. I was able to include about 35 participants in total-14 interviewees and 21 survey responses, although the exact number cannot be determined because there may be some overlap, since some of my interviewees may have completed the anonymous online survey as well.

Before I began the procedure for gathering data, I spoke with Cronin to discuss this topic in depth and to get the perspective of an expert in the field. After reviewing my ideas, she helped me finalize the materials necessary for my project and the manner in which I should collect my

\footnotetext{
${ }^{1}$ Cronin, Kerry. "Intimacy: It’s Complicated.” C21 Resources Spring 2014: 2-5. Print.

${ }^{1}$ Cronin, Kerry. "Rules of the 1st Date." The Boston College Church in the 21st Century. Webcast. 14 Feb. 2010.
} 
data. First, I spoke with five male students and five female students in person, and I presented each of them with three scenarios depicting different types of college relationships:

1. John and Mary are sophomores that have been friends for a few months at BC. They normally hang out in a group setting, but one day John asks Mary, "Do you want to get coffee or something this weekend?" The two get coffee, and continue to have similar meet-ups over the next few weeks. How would you describe John and Mary in this scenario?

2. Nick and Jessica go out to dinner every Saturday night, and sometimes Jessica stays over at Nick's room for the rest of the night. During the week they hold hands on their way to class, and they frequently buy each other gifts and use hugs and kisses to show their affection. How would you describe Nick and Jessica in this scenario?

3. Mike and Gina met one weekend at a Mod party, and that night they ended up making out. Mike and Gina say hi when they see each other on campus, but they have no contact besides that. The next weekend, they see each other again, and they decide to exchange phone numbers. How would you describe Mike and Gina in this scenario?

I read the scenarios aloud, and then wrote down everything that the students said - some giving longer, more detailed responses, and some giving single-word descriptors (see Appendix A). All responses were transcribed verbatim during the interviews, and no recording devices were used. Next, I administered an online survey, which consisted of four questions with a few parts each, to 21 students, 11 male and 10 female. The questions are as follows:

1. "What is your gender?" (male or female)

2. "Indicate how frequently you hear the following phrases around campus in regards to the college dating scene." The left hand column featured a series of phrases, which were randomized for each participant:

They are going to date

They are going on a date

They are seeing each other

They are hooking up

They are in love

They are boyfriend/girlfriend

They are a thing

They are a couple

He/she is a hook-up

He/she asked her/him on a date

He/she asked her/him out

They're in a relationship

They are more than friends

They are dating

On the top row, participants had the option of selecting how frequently they hear each phrase, which the options being: Very Often, Often, Somewhat, Rarely, Never, N/A

3. "Indicate how frequently you personally use the following terms in conversations about dating on campus." The format was the same as above, with the same options, except participants had to indicate how frequently they personally use the terms, as opposed to how often they hear them. 
4. "Rank the following terms describing the various stages of college dating, with Level 1 indicating the early stages of a relationship, and Level 4 indicating a longer, more developed relationship. You may assign more than one term to the same category." Again, options were randomized for each participant.

\author{
Seeing each other \\ Talking to each other \\ Being in a relationship \\ Being boyfriend/girlfriend \\ Being a couple \\ Going on dates \\ Hanging out \\ Hooking up \\ Dating \\ Being a thing
}

I began with the scenarios to allow my subjects to generate language themselves, in order to test the first part of my hypothesis about the performance aspect of male versus female college dating language. I then used the survey as a "recognition model," as Cronin called it, to see how the attitudes about certain phrases compare and contrast across gender.

The final part of my study involved an interview of a real BC couple and their "friend group"another term used by Cronin to describe the friends that are "invested" in the relationship of a couple in their group. The names have been changed to preserve anonymity; the boyfriend and girlfriend will be named Jack and Jane, respectively. I interviewed both of them separately, and then I interviewed two of their very close friends: Jane's best friend, who will be called Eric, and Jack's close friend, who will be named Sarah. The purpose of this was to see how Jack and Jane defined the various stages of their relationship, and to see if their timelines matched up, as well as to see how their friends weigh-in on their relationship and how they use language to define the different stages of their friends' romance.

\title{
RESULTS
}

For the first part of my study involving scenarios, the general attitudes about each situation were similar, although the language used had interesting similarities and differences among men and women. For the three scenarios, generally all male and female participants came to a consensus: the first couple was not dating but still interested in each other, the second was dating/in a relationship, and the third was a little more difficult to define since they engaged in the hook-up culture but exchanged phone numbers, which is usually indicative of more serious interest. One common feature of the male speech was the use of adverbs such as "clearly" to emphasize their definitions, such as "They're clearly dating" or "John is trying to pursue a relationship, clearly" (Appendix A; M1, M2). Several male participants also felt the need to emphasize that the first pair was not dating (M1, M4). This would coincide with Cronin's claim that men tend to assign two categories, dating and not dating, and the use of "clearly" could also relate to Cronin's point that "guys want a label" and feel the need to establish clarity. A variety of terms was used by the males to describe the second scenario, such as "dating," "boyfriend and girlfriend," and "together," while for the third, most of them used variations of the phrase "hooking up," or "interested in each other," and one even used "friends with benefits" (M1, M2, M3, M5). 
Female students tended to use a more narrative structure, going into more lengthy descriptions and explanations rather than using one or two-word definitions. For the first question, they avoided directly addressing the concept of dating, using words that marked uncertainty or hesitance, such as "the possibility of something more," "might be moving toward dating," and "potential for dating" (Appendix A; F1, F3). For the second question, two girls used the phrase "in a relationship," one used "boyfriend/girlfriend," and two used the phrase "dating" (F1 - F5). For the third, the girls generally agreed that the students were hooking up, but they were reluctant to put a label on it: one said, "I don't have any label for that, but there's an interest," and another even described the students as "nothing" (F4, F5). Cronin mentioned how in the "hook-up script" - the language used to describe the hook-up culture among college students - the vagueness of the script is valued because there's a lack of specificity, and it gives the "status" of being part of the culture without having to divulge the exact details. This linguistic tendency seems to coincide with the interviewees' responses; none of them limited responses to "they are hooking up," and instead felt the need to add explanatory statements or express uncertainty (see Appendix A, Question 3 responses).

The results of the survey were a bit more sporadic in terms of individual results, but the overall averages were generally similar among men and women. The first table below indicates the average responses to question 2, "Indicate how frequently you hear the following phrases around campus in regard to the college dating scene." The second table shows the results from question 3, "Indicate how frequently you personally use the following terms in conversations about dating on campus." The average ratings are based on a scale of $1-5$ with $1=$ Never, 2=Rarely, 3=Somewhat, 4=Often, and 5=Very Often.

TABLE 1 (question 2 results)

Key: $1=$ Never, $2=$ Rarely, $3=$ Somewhat, $4=$ Often, and $5=$ Very Often

\begin{tabular}{|c|c|c|}
\hline & Average Rating & \\
\hline Dating Phrase & Males & Females \\
\hline They are dating & 4.2 & 3.8 \\
\hline They are boyfriend/girlfriend & 3.7 & 3.1 \\
\hline They are seeing each other & 3.2 & 2.1 \\
\hline They are a thing & 3.5 & 3.8 \\
\hline They are a couple & 3.7 & 2.6 \\
\hline They are hooking up & 4.2 & 4.0 \\
\hline They are in a relationship & 3.3 & 2.7 \\
\hline They are going on a date & 2.5 & 2.5 \\
\hline He/she is a hook-up & 3.1 & 3.1 \\
\hline He/she asked him/her on a date & 3.0 & 2.2 \\
\hline He/she asked him/her out & 4.3 & 2.9 \\
\hline They are going to date & 2.9 & 1.8 \\
\hline They are more than friends & 3.0 & 2.4 \\
\hline They are in love & 2.3 & 1.7 \\
\hline
\end{tabular}


TABLE 2 (question 3 results)

Key: $1=$ Never, $2=$ Rarely, $3=$ Somewhat, $4=$ Often, and $5=$ Very Often

\begin{tabular}{|c|c|c|}
\hline & $\begin{array}{c}\text { Average } \\
\text { Rating }\end{array}$ & \\
\hline Dating Phrase & Males & Females \\
\hline They are dating & 3.6 & 3.6 \\
\hline They are boyfriend/girlfriend & 3.1 & 3.2 \\
\hline They are seeing each other & 1.9 & 2.0 \\
\hline They are a thing & 3.0 & 3.8 \\
\hline They are a couple & 3.4 & 3.1 \\
\hline They are hooking up & 2.3 & 2.9 \\
\hline They are in a relationship & 3.1 & 2.4 \\
\hline They are going on a date & 2.1 & 2.2 \\
\hline He/she is a hook-up & 1.7 & 2.2 \\
\hline He/she asked him/her on a date & 3.1 & 2.0 \\
\hline He/she asked him/her out & 3.1 & 2.8 \\
\hline They are more than friends & 1.9 & 1.7 \\
\hline They are in love & 2.0 & 1.8 \\
\hline
\end{tabular}

As seen in Table 1, the phrases overheard most frequently by male and female subjects were both "They are dating" and "They are hooking up," and the phrases heard the least often were "They are in love" and "They are going to date." In terms of language performance, the phrases used most often by men were "They are dating" and "They are a couple," while the ones used most by women were "They are dating" and "They are a thing" (Table 2). The word "date" takes on a verb form to describe a continuing relationship, while nouns such as "couple" and "thing" objectify the pair and seem to indicate them as a single entity rather than addressing them individually. The phrases, "They are seeing each other," "They are more than friends," and "They are in love" were used least often by both men and women. Overall, the male averages are generally higher than those of the females, indicating that men tended to hear these phrases more often in conversation. As for the use of language, women's responses seem to be more scattered, while men tended to be more consistent in their responses.

For the final segment of my research, the couples interviews, both students said they would describe themselves as either boyfriend and girlfriend or dating, although Jack asked me if I could give him options, while Jane was able to generate the language herself before I gave her choices. Interestingly, when asked to identify when Jack became interested in Jane, Jack immediately referenced a party when he started to show interest, whereas Jane replied, "April of 2013," and then described the party after I prompted her. When asked to describe the point when they were officially boyfriend and girlfriend, they both said that there wasn't really a dating period and a relationship period; the two coincided, and they only became "official" after putting their relationship status on Facebook. Their friends had similar perceptions and timelines regarding the progress of the relationship, although Eric was able to provide more specific details than Sarah. For example, when asked, "At what point did they become a thing?" Eric responded, "Two weeks after the first date," while Sarah said, "I think it was right before summer started, after finals. I knew because I saw it on Facebook." This could be an indication that the girlfriend divulges more details to her friend than the boyfriend does, and therefore has a tendency to use more language in conversation about dating than her boyfriend. This cannot be certain, since it may be an issue of how close the pairs of friends are, which was unstated at the time of the interview. As for labeling the relationship, Eric described them as "in a relationship," while 
Sarah said they were "dating," which was contrary to my expectations, although Eric might be closer friends with Jane and therefore have a better understanding of her relationship with Jack.

\section{Discussion}

The data collected reveal interesting trends regarding the use of language among men and women to describe college dating, and there are definitely some aspects that support the first part of my hypothesis: males tend to use more limited vocabulary and language to describe college dating stages than females do. The scenario responses best exemplify this, as the boys tended to give shorter, one-sentence responses (Appendix A M1, M3), while girls had longer, more narrative responses (Appendix A F1, F3, F4). This wasn't the case for all of the respondents, so it's difficult to make a generalization, but I did notice that the males I interviewed tended to respond more quickly, while females put more consideration into their responses (indicated by "um" and "hm"). In addition, I noticed that the male subjects felt a need to emphasize what the relationship is not, rather than what it is, whereas females took a different approach and were hesitant to define the relationship, using a larger variety of terminology to aid in the process. The tendency to use negation among the males is evidenced by phrases such as "They're clearly not dating," "I wouldn't describe them as more than that," "Nothing else to describe it," and "Not much above acquaintances."

The males used a wider variety of terms than I expected, including "hook-up buddies," "hanging out," "together," "interested in each other," and "friends with benefits." On the whole, however, it seems like the females had a more expansive range of performance - or, at the very least, they used phrases outside the conventional terms used by the males, such as "one-onones," "they're talking," and "acquaintances with benefits." In addition, the female subjects used modifiers often to avoid making a definite claim about each scenario, and they seemed overall more hesitant to assign a particular label to each one. Words such as "possibly," "might," "potential" and "probably" were common in their speech, and some even formed their responses as a question. When they did make a claim, they often weren't able to merely say "they are dating" or "they are boyfriend/girlfriend" as the males did — rather, there were additional modifying adjectives placed before the labels to make further distinctions. Examples of this feature include, "I would think they're boyfriend/girlfriend," "serious relationship," "casual hook-up," and "definitely exclusive." Another interesting aspect was that the girls tended to respond using the same language of "would" that I used in the question - they responded "I would say," while the boys just stated their answer without including a performative verb before the answer. This would suggest that females do tend to draw attention to their performance, which was not the intention of my study, but may be a worthy topic to consider in the future.

The data collected from the surveys seems to support the second half of my hypothesis, which is that men and women have the same attitudes about the different forms of dating, although neither the scenarios nor the survey support my claim that college students avoid using language directly related to a date or dating. On average, males tended to give a higher rating on questions 2 and 3 for phrases indicative of more serious relationships, such as "boyfriend/girlfriend," "a couple," and "in a relationship," and they also claimed to hear or use phrases related to asking someone out or asking someone on a date more often than girls do (Table 1,2). When comparing the phrases overheard to the phrases actually used between men and women, it also seems that female students generally assigned the same frequency to observing and speaking these phrases, whereas male students tended to assign a lower frequency in question 3 when asked about their own verbal usage of the terms. The responses to question 4, 
summarized in Table 3 below, indicate that males and females do have similar attitudes about the seriousness of the various levels of college dating, as indicated by very close averages. The males were the only ones to agree completely on the rankings of the terms "being a couple" and "talking to each other," rated a level 4 and a level 1 by each respondent, respectively. It's as if the male students agree on both extremes of a relationship, from least serious to most serious, while they are unsure of the in-between stages, furthering Cronin's point that "men are unsure of when things are changing," and so they need someone to articulate for them the distinctions between each phase.

TABLE 3 (question 4 results)

Key: Level 1 indicates the early stages of a relationship, and Level 4 indicates a more developed relationship.

\begin{tabular}{|c|c|c|}
\hline Dating Term & $\begin{array}{c}\text { Average Rating for Females } \\
\text { (Level 1-4) }\end{array}$ & $\begin{array}{c}\text { Average Rating for Males (Level } \\
\text { 1-4) }\end{array}$ \\
\hline Dating & 3.11 & 3.33 \\
\hline Going on dates & 2.22 & 2.44 \\
\hline Being a thing & 1.89 & 4.56 \\
\hline Being a couple & 3.56 & 1.89 \\
\hline Hooking up & 1.44 & 3.78 \\
\hline Being in a relationship & 3.89 & 3.67 \\
\hline Being boyfriend/girlfriend & 3.56 & 2.33 \\
\hline Seeing each other & 2.44 & 1.00 \\
\hline Talking to each other & 1.33 & \multicolumn{2}{|}{} \\
\hline Hanging out & 1.11 & 1.22 \\
\hline
\end{tabular}

One of my findings does not relate directly to my hypothesis, but could be studied further: the use of the phrase "to be a thing" appeared much more frequently in female speech than male speech. It was first mentioned by subject F3 to describe the couple in the first scenario, and in the survey, the average rating for this phrase was higher among women (3.8) than men (3.0). Even Jane said in her couple interview, "I'd say 'we're a thing.' I tend to say that a lot." After asking her when Jack became interested in her, she recounted, "I told him straight up, what do you mean, and he said, 'If given the opportunity, I would date you.' Like, who says that?" These short phrases reveal quite a great deal about her perceptions on linguistic features of the dating scene, by claiming it's more acceptable to describe a relationship as "a thing" than to say to someone that you would like to date him or her.

\section{CONCLUSION}

While I was able to dip into the linguistics of college dating, there are definitely some changes I would have made to my study if given the opportunity in order to get stronger support or denial of my hypothesis. I would have conducted more interviews and even had each of my subjects who I interviewed complete the survey after the interview, so I could directly compare their performance to their recognition, rather than observing these as two separate entities. I would have used a sample of students more representative of the Boston College population, since I was only able to talk to people that I come in contact with on a regular basis. In addition, other factors should be taken into consideration, since an individual's language may vary depending on past dating history, current relationship status, and sexual identity. I realized after conducting this study that there are so many elements to consider, and I would be interested in exploring the various facets in the future. For the purposes of this study, however, it's evident 
that language is used differently among females and males in regards to college dating. While both genders tend to have similar attitudes about the subject, it seems that men and women have different corpora of language to be used in certain situations. And perhaps they even realize this, raising the question of how self-aware male and female students are of these differences. 


\title{
APPENDIX
}

\section{A) SCENARIO RESPONSES}

\author{
Male subjects
}

M1

1. "They're clearly not dating."

2. "They're clearly dating."

3. "They're hook-up buddies."

M2

1. "If John has romantic feelings for Mary, then I think John is trying to pursue a relationship, clearly, but if Mary does not have romantic feelings for John, then she probably does not notice his romantic endeavors."

2. "They are boyfriend and girlfriend."

3. "Mike and Gina are victims of the infamous BC hook-up culture."

M3

1. "I would describe them as hanging out."

2. "Together."

3. "Interested in each other."

M4

1. "They are friends who are flirting with the idea of dating. But I wouldn't describe them as more than that."

2. "They are dating. Boyfriend and girlfriend."

3. (pause) "They hooked up, but they're thinking of being something more because they exchanged phone numbers."

M5

1. "Friends on a consistent basis. Nothing else to describe it. I have a friend who I get lunch with every week. I see [my girlfriend] much more consistently. I don't think I can draw any other conclusion.”

2. "That's a relationship."

3. "Not much above acquaintances. At best I'd describe them as friends with benefits."

\section{Female Subjects}

F1

1. "I would say that they are still friends but with the possibility of something more. They might be moving towards dating."

2. "I would say that they are in a relationship."

3. "Um, hm. Acquaintances with benefits? It sounds like they hooked up once and might consider doing that again."

F2

1. "They're dating."

2. "Uh, they're in a serious relationship."

3. "Hm. They hooked up and are talking."

F3

1. 'Hm. I would say there's potential for dating there. I think they both should be thinking that that's a possibility if they're just having not-group setting meet-ups. One-on-ones. My initial reaction would be, oh there might be a thing there."

2. "I would think they're boyfriend/girlfriend."

3. "Um, they sound like a casual hook-up, but now that they're exchanging numbers there's a potential for friendship. Sounds like a typical BC thing. No serious intentions there." 
1. "I would say that they were getting to know each other on a more personal basis as friends, but I wouldn't say there was anything romantic about the relationship."

2. "They are definitely dating and probably have been dating for at least a few months. It doesn't sound like a new relationship. Definitely exclusive."

3. "I would say because they exchanged phone numbers that are genuinely interested, but I wouldn't have a label on that relationship at all. Definitely a general interest, friends, hook-up buddy. I don't have any label for that, but there's an interest."

F5

1. "They're "talking",

2. "Dating."

3. "Nothing. One-time hook-up.

\section{B) Couple InTerviews}

1) Boyfriend (Jack)

Q: How would you describe or define your relationship currently? (he did not know how to respond and asked for examples so then I gave him options). Would you say you are boyfriend/girlfriend, a couple, in a relationship, dating, or a combination?

A: Dating, boyfriend/girlfriend, seeing each other. Pretty comfortable with using them interchangeably.

Q: When did you first become interested in your girlfriend?

A: There was a party in my room after the winter dance last year and so it was a fairly small party, 10-12 people. I kept trying to hit on her and was trying to get her attention, to which I guess she was oblivious. She was more interested in my friend. She either wasn't completely aware or she was more interested in my friend.

Q: At one point did you guys transition from casually hanging out to dating?

A: It's not that simple. At another party later that year, I made references to the previous night that I mentioned. Kind of made her aware and said pretty straight forward that I was interested in dating her. She said, "If you mean it, then you'll call me the next day when you're sober." I literally saw her the next day for a performance, asked, "do I still need to call you?" and she said yes. I called her an hour later and made dinner plans at Tasca the same night. Nothing happened at the party and that was it. No hook-ups, no nothings. 27th of April was the party, technically the 28th for first date.

Q: When did the two of you become boyfriend/girlfriend?

A: Oh no, she'll probably give me shit for this. I don't know if we picked an actually day, but I remember that we officially put in on Facebook, but that was several weeks later. I was checking with her to make sure that was okay. There's no date that sticks out to me. First day we started dating, and not an official boyfriend/girlfriend. No established date. I think she'll give me shit for this.

2) Girlfriend (Jane)

Q: How would you describe or define your relationship currently?

A: Boyfriend and girlfriend. We're a thing.

Q: Would you say you are boyfriend/girlfriend, a couple, in a relationship, dating, or a combination?

A: Boyfriend/girlfriend and dating.

Q: When did your boyfriend first become interested in you?

A: April of 2013. I told him straight up, what do you mean, and he said, "If given the opportunity, I would date you." Like, who says that? I told him that if he called me when I was sober, I would consider it. 
Q: At what point did you guys transition from hanging out to actually dating?

A: It was kind of automatic. We went on that date and I don't think we went on many more before we were like, "So you're my boyfriend now. It's official." It was during finals week, so there was a lot of hanging out, going around the Res, things like that. It was very low key. I don't think there were a whole lot of dates in there.

Q: So did you actually make a point of stating when you were official?

A: Yeah, we had very briefly talked about it. I remember my roommates were like, so are you official or not? After finals were over, I think middle of May we put in on Facebook and that was how we made it official. I don't think there was ever a question. After hanging out a couple of times, it was obvious that that was where it was headed. 